\title{
Evaluating the Water Vapor Transmission Properties of Summer Cooling Towels
}

\author{
Yim-Ling Lam ${ }^{1}$, Wenyi Wang ${ }^{1, \mathrm{a}}$, Chi-Wai Kan ${ }^{1, \mathrm{~b}}{ }^{*}$, Nongnut Sasithorn ${ }^{2, \mathrm{c}}$, Kongkiat Maha-in ${ }^{2, \mathrm{~d}}$,Lavanchawee \\ Sujarittanonta ${ }^{3, \mathrm{e}}$, Sarunya Puakpong ${ }^{4, \mathrm{f}}$ Rattanaphol Mongkholrattanasit ${ }^{2, \mathrm{~g}}$ * \\ ${ }^{1}$ Institute of Textiles and Clothing, The Hong Kong Polytechnic University, Hung Hom, Hong Kong, China. \\ ${ }^{2}$ Faculty of Industrial Textiles and Fashion Design, Rajamangala University of Technology Phra Nakhon, Bangkok, Thailand \\ ${ }^{3}$ Faculty of Science \& Technology, Rajamangala University of Technology Phra Nakhon, Bangkok, Thailand \\ ${ }^{4}$ Department of Home Economics, Faculty of Agriculture, Kasetsart University, Bangkok, Thailand
}

\begin{abstract}
This study evaluated the cooling properties of summer cooling towels of different brands by studying the water vapor transmission behavior. All the samples were found to provide a cooling effect at first contact after being wetted. The samples of N-rit showed the highest cooling effect followed by Cooldyxm and Ice Towel, whereas Perfect Fitness had the poorest cooling effect.
\end{abstract}

\section{Introduction}

In recent years, functional fabrics have developed rapidly in the market. Because of global warming, extreme hot days in Hong Kong frequently occur in summer, resulting in a large demand for textile products with cooling effects. Cooling towels of different brands are popular in Hong Kong since the products are claimed to provide excellent cooling effect helping people to reduce body temperature.

Thermal comfort was defined as "that condition of mind which expresses satisfaction with the thermal environment" by American Society of Heating, Refrigerating and Air-Conditioning Engineers, Inc.[1]. Reversely, thermal discomfort for human is that the dissatisfaction with the ambient surrounding.

Human thermal comfort is significantly influenced by heat and humidity. During summer, high temperature can lead to an increase in human's body temperature. When human's body temperature rises, heat is released and dissipated through sweating which increases skin wetness particularly in high humidity condition [2].

Since skin wetness leads to thermal discomfort, the perspiration is the main factor causing thermal discomfort
[3]. This can be evaluated by measuring the water vapor transmission property of fabrics, which refers to 'the rate of water vapor flow through unit area of the surface of fabric in an environment under specific humidity and temperature [4]. In this study, four types of cooling towels, i.e., Perfect Fitness, Ice Towel, N-rit and Cooldyxm, were selected to analyze the cooling effects by evaluating the water vapor transmission.

\section{Experimental}

\subsection{Fabric samples}

Four cooling towels were obtained from four different brands through chain stores, online shop or street store in Hong Kong and China market. These tested products have different fiber contents, fabric structure and thickness but all of them provide the cooling function with water. The present study aims to compare the product of chain store with online store and street store. The specification of each sample was shown in Table 1.

All samples were conditioned with the temperature at $20 \pm 2{ }^{\circ} \mathrm{C}$ and the relative humidity at $65 \pm 2 \%$ for 24 hours before testing.

Table 1. Specification of tested samples.

\begin{tabular}{|c|c|c|c|c|}
\hline Item & \multicolumn{4}{|c|}{ Sample specification } \\
\hline Brand & Perfect Fitness & N-rit & Cooldyxm & Ice Towel \\
\hline Composition & $100 \%$ PVA & $\begin{array}{c}92 \% \text { Polyester } \\
8 \% \text { Spandex }\end{array}$ & $100 \%$ Polyester & $100 \%$ Polyester \\
\hline Size/cm & $73 \times 27$ & $99 \times 19.7$ & $108 \times 31$ & $88 \times 35$ \\
\hline Type & Composite fabric & Knit & Knit & Knit \\
\hline $\begin{array}{c}\text { Fabric weight } \\
\left(\mathrm{g} / \mathrm{m}^{2}\right)\end{array}$ & 360.16 & 131.43 & 165.05 & 194.09 \\
\hline Fabric thickness $/ \mathrm{mm}$ & 1.95 & 0.40 & 0.61 & 0.62 \\
\hline Yarn linear density/ & 32.3 & 15.7 & 18.5 & 21.4 \\
\hline
\end{tabular}

wangwenyi1111@gmail.com ${ }^{\mathrm{a}}$, tccwk@polyu.edu.hk ${ }^{\mathrm{b}}$, nongnut.s@rmutp.ac.th ${ }^{\mathrm{c}}$, kongkiat.m@rmutp.ac.th ${ }^{\mathrm{d}}$,

Lavanchawee@hotmail.com ${ }^{\mathrm{e}}$, agrsek@ku.ac.th ${ }^{\mathrm{f}}$, rattanaphol.m@rmutp.ac.th ${ }^{\mathrm{g}}$ 


\begin{tabular}{|c|c|c|c|c|c|}
\hline \multicolumn{2}{|c|}{ Tex } & & & & \\
\hline \multirow{2}{*}{$\begin{array}{c}\text { Fabric } \\
\text { density }\end{array}$} & Wale/cm & 7 & 18 & 18 & 17 \\
\cline { 2 - 6 } & Course/cm & 6 & 24 & 22 & 18 \\
\hline
\end{tabular}

\subsection{Water vapor transmission evaluation}

Water vapor transmission refers to "the rate of water vapor flow through unit area of the surface of fabric in an environment under specific humidity and temperature. In this study, water vapor permeability of the fabric is determined by evaluating the rate of vapor movement and transmission out of the water cup to controlled surrounding through the fabric using the water cup method. The test result is expressed by weight difference of water cup in grams after 24 hours.

The fabrics were first cut into circle shape with a diameter of $6.5 \mathrm{~cm}$, two circle pieces for 1 brand and 8 pieces of circle fabrics in total. The plastic cups were filled with distilled water to a level below the top $1 \mathrm{~cm}$. Then, the fabrics were attached to the sealed cups with right side faced upward. The cups with fabrics covered were weighted by the electronic balance and the weight was recorded. After the fabric samples were sealed to the cups, they were placed under standard condition for at least 24 hours.

Water vapor transmission can be calculated by Eq. 1 . The weight loss of the cups is caused by the water vapor transmission through the fabrics. The higher the value of water vapor transmission, the better the transmission ability of the fabrics, and hence the fabric can transfer more vapor from body to outer surrounding.

$$
\mathrm{WVT}=\frac{G}{t A}
$$

Where, WVT is water vapor transmission rate $(\mathrm{g} / \mathrm{h}$ $\mathrm{m}^{2}$ ); $\mathrm{G}$ is weight change, $\mathrm{g}$; $\mathrm{t}$ is 24 hours, $\mathrm{h}$; $\mathrm{A}$ is the area of cup mouth, $\mathrm{m}^{2}$.

\section{Results and Discussion}

\subsection{Water vapor transmission analysis}

Water vapor transmission refers to the ability of fabric transporting the moisture vapor to the environment. The higher result means better vapor transport ability to keep the fabric dry. From Figure 1, N-rit had the highest value of mean water vapor transmission $\left(50.993 \mathrm{~g} / \mathrm{h} \cdot \mathrm{m}^{2}\right)$, followed by Cooldyxm $\left(48.119 \mathrm{~g} / \mathrm{h} \cdot \mathrm{m}^{2}\right)$, Ice Towel $\left(45.045 \mathrm{~g} / \mathrm{h} \cdot \mathrm{m}^{2}\right)$ and Perfect Fitness $\left(41.570 \mathrm{~g} / \mathrm{h} \cdot \mathrm{m}^{2}\right)$. The results indicate that N-rit can transfer water vapor quickly from fabric to outer environment, which may be affected by fabric thickness and yarn count.

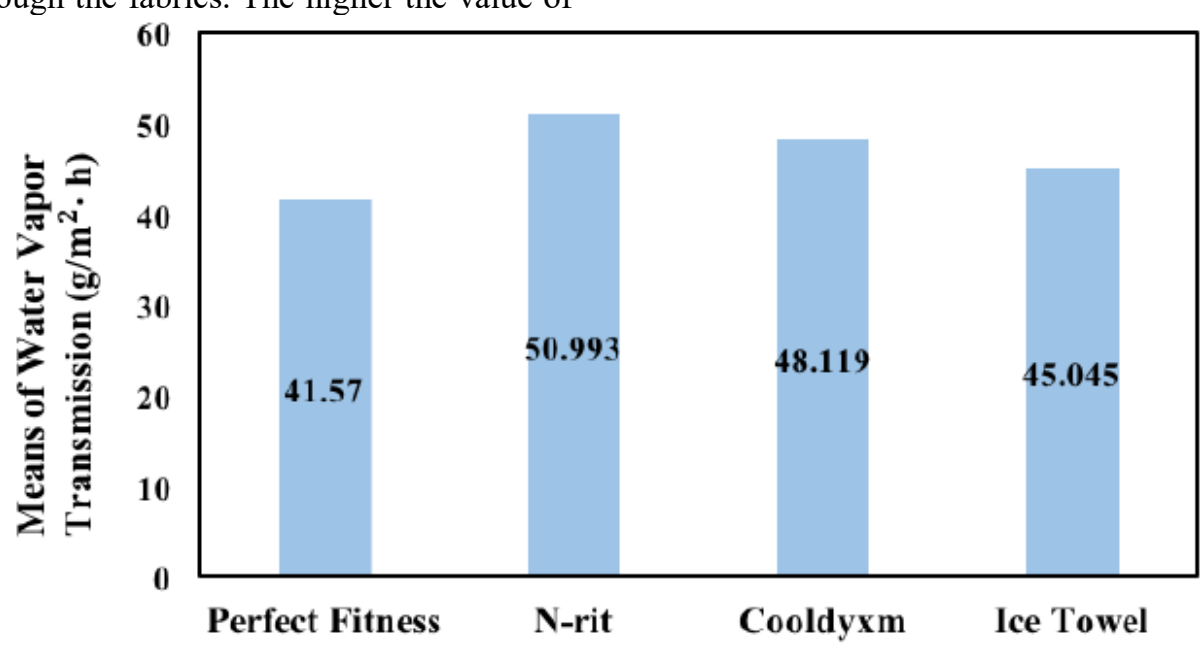

Figure 1. Means of water vapor transmission of four types of samples.

\subsection{Relationship between fabric content and water vapor transmission}

Fiber material is one of the factors affecting water vapor transmission [5]. For transporting and evaporating water vapor to outer surrounding, the vapor should be absorbed, diffused and transferred to the outer surface of fabrics [6]. Hydroscopic fibers tend to absorb a large quantity of water vapor due to its high capacity of humidity absorbency and moisture regain. Hence, the fabric made of hydroscopic fibers may have low water vapor transmission since the water molecules are absorbed by the fibers and this may not be easy to diffuse and evaporate the molecules to the surface quickly.

As shown in Figure 1, Perfect Fitness had lower water vapor transmission due to its higher moisture regain of PVA (4.5\%-5\%), compared to N-rit and Cooldyxm made of polyester $(0.4 \%)$. Therefore, $\mathrm{N}$-rit and Cooldyxm could transport and evaporate the vapor molecules quickly from the fabric surface than Perfect Fitness. Moreover, although Ice Towel was made of polyester, the water vapor transmission was the second lowest, which may be due to other fabric parameters such as the thickness and yarn count. 


\subsection{Relationship between fabric thickness and water vapor transmission}

It was reported that increasing the fabric thickness would worsen the diffusion ability of the fabric because the porosity of the material would be reduced [7]. The correlation shows that the higher the fabric thickness, the lower the water vapor transmission. On the basis of the correlation analysis from Table 2, the $p$-value and the $r$ value were $0.004(<\alpha=0.01)$ and -0.883 ( $r>0.7$, strong correlation), respectively. It was found that fabric thickness and water vapor transmission were strongly and negatively correlated and such relationship was statistically significant in $99 \%$ confidence.

Figure 2 shows a negative relationship between the fabric thickness and water vapor transmission. The thinnest and the thickest fabrics were observed in N-rit $(0.4 \mathrm{~mm})$ and Perfect Fitness $(1.95 \mathrm{~mm})$, respectively. Therefore, N-rit sample was the best product in terms of water vapor transmission while the poorest towel was Perfect Fitness sample regarding the cooling effect.

Table 2. Correlation between fabric thickness and water vapor transmission.

\begin{tabular}{|c|c|}
\hline & $\begin{array}{c}\text { Fabric thickness } \\
(\mathrm{mm})\end{array}$ \\
\hline water vapor transmission $\left(\mathrm{g} / \mathrm{h} \cdot \mathrm{m}^{2}\right)$ & $-0.883^{* *}$ \\
Pearson correlation & 0.004 \\
Sig. (2-tailed) & \\
\hline
\end{tabular}

${ }^{* *}$ Correlation is significant at the 0.01 level (2-tailed).

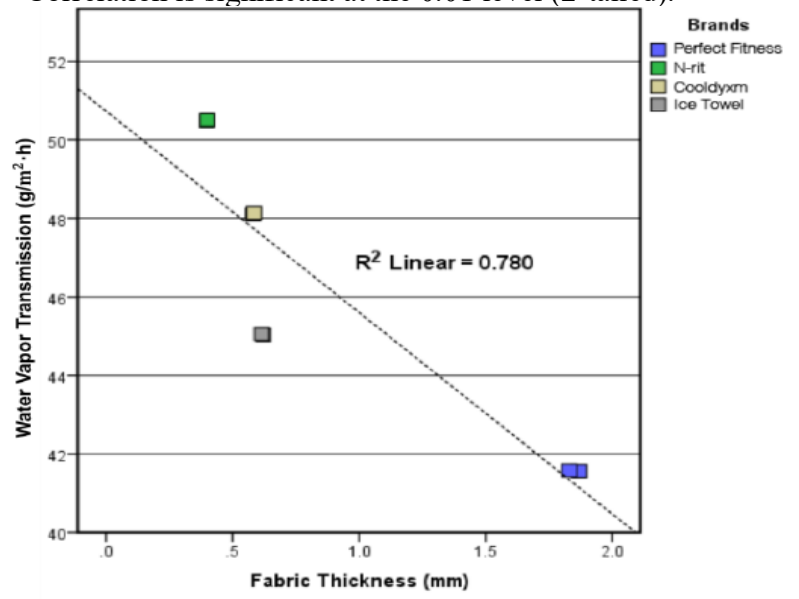

Figure 2. Relationship of fabric thickness and water vapor transmission.

\subsection{Relationship between yarn count and water vapor transmission}

Majumdar and coworkers found that the finer the yarn, the greater the water vapor transmission ability of the fabric, which was in accordance with the results of this study [8]. Based on the correlation analysis (Table 3), $p$-value and the $r$-value were $0.000(<\alpha=0.01)$ and $-0.958(\mathrm{r}>0.7$, strong correlation), respectively. It was found that yarn count and water vapor transmission was strongly and negatively correlated. It was proved that in this case the finer the yarn, the better the water vapor transmission of the fabric.
Table 3. Correlation between yarn count and water vapor transmission.

\begin{tabular}{|c|c|}
\hline & $\begin{array}{c}\text { Yarn count } \\
(\text { Tex })\end{array}$ \\
\hline water vapor transmission $\left(\mathrm{g} / \mathrm{h} \cdot \mathrm{m}^{2}\right)$ & $-0.958^{* *}$ \\
Pearson correlation & 0.000 \\
Sig. (2-tailed) & \\
\hline
\end{tabular}

$* *$ Correlation is significant at the 0.01 level (2-tailed).

As shown in Figure 3, a negative relationship between yarn count and water vapor transmission was presented. The yarn of N-rit was the finest while Perfect Fitness was the coarsest, indicating that N-rit had higher water vapor transmission than Perfect Fitness.

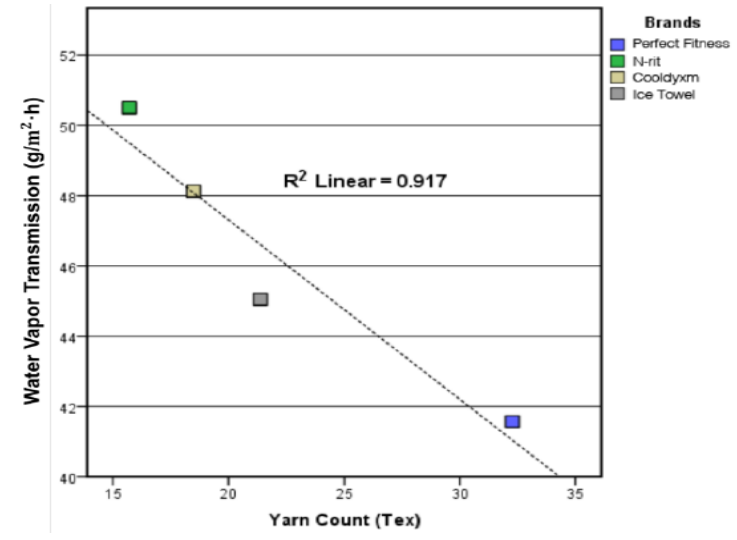

Figure 3. Relationship of yarn count and water vapor transmission.

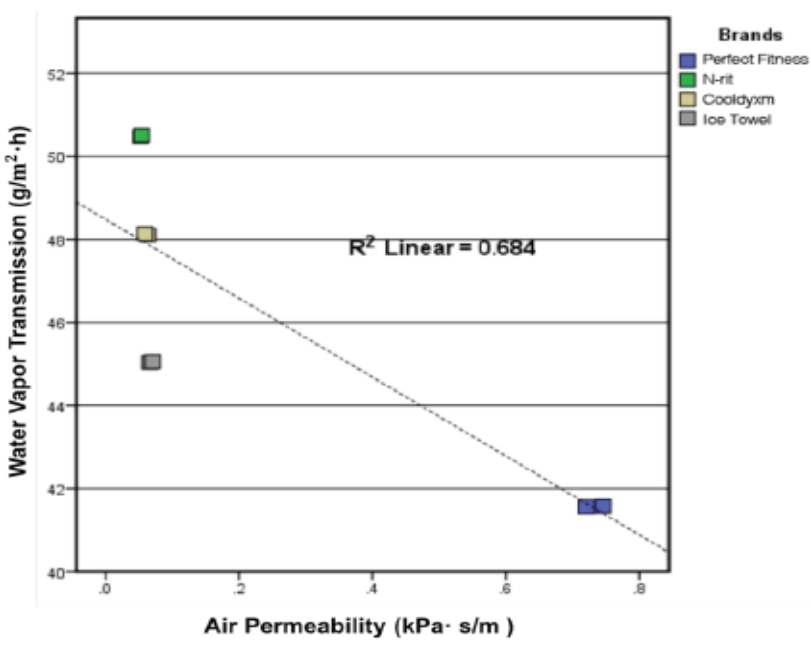

Figure 4. Relationship of air permeability and water vapor transmission.

\subsection{Relationship between air permeability and water vapor transmission}

It was noted that fabric with high air permeability would transfer water rapidly to outer surface since the increase in air permeability would lead to an increase of moisture permeability [9]. Table 4 shows the correlation of the air permeability and water vapor transmission. As the $p$-value was $0.011(<\alpha=0.05)$ and the $r$-value was $-0.827(\mathrm{r}>-0.7$, strong correlation), thus air permeability was strongly and negatively correlated with water vapor transmission. The 
lower the air permeability result, the higher the air permeability property, and thus the greater the water vapor transmission of the fabric.

From Figure 4, the curve was shown with a negative slope between air permeability and water vapor transmission. As the air permeability of N-rit sample was the best, the water vapor transmission was also the greatest. By contrast, Perfect Fitness had the worst air permeability, its water vapor transmission was the poorest. Both air permeability and water vapor transmission were negatively correlated with the fabric thickness. The thinner the fabric, the better the air permeability and water vapor transmission. Thus the air permeability results were negatively correlated with water vapor transmission.

Table 4. Correlation between air permeability and water vapor transmission.

\begin{tabular}{|c|c|}
\hline & $\begin{array}{c}\text { Air permeability } \\
(\mathrm{kPa} \cdot \mathrm{S} / \mathrm{m})\end{array}$ \\
\hline Water vapor transmission $\left(\mathrm{g} / \mathrm{h} \cdot \mathrm{m}^{2}\right)$ & $-0.827^{* *}$ \\
Pearson correlation & 0.011 \\
Sig. (2-tailed) & \\
\hline
\end{tabular}

**Correlation is significant at the 0.05 level (2-tailed).

\section{Conclusion}

In this study, the water vapor transmission properties of summer cooling towels of different brands available in Hong Kong market were comparatively evaluated. All the samples were found to provide a cooling effect at first contact after being wetted. The samples of N-rit showed the highest cooling effect, followed by Cooldyxm and Ice Towel. Perfect Fitness was the poorest sample in terms of water vapor transmission, which may be affected by fabric thickness and yarn count.

\section{Acknowledgement}

Authors would thank the financial support from The Hong Kong Polytechnic University for this work. Authors gratefully acknowledge the help of Rajamangala University of Technology Phra Nakhon for supporting this research.

\section{References}

1. American Society of Heating, Refrigerating and AirConditioning Engineers, Inc. ASHRAE Standard: Thermal Comfort Conditions. ASHRAE Standard, New York, 55-66, 1966.

2. Heidorn, K. C. Summer Discomfort: Mixing Heat and Humidity. Retrieved from http://www.islandnet.com/ see/weather/life/heat.htm, 1998.

3. Winslow, C.E.A., Herrington, L.P., \& Gagge, A.P. Physiological reactions and sensations of pleasantness under varying atmospheric conditions. ASHVE Transactions, 44 (1939) 179-194.

4. ASTM International. (2016). ASTM E96 / E96M-16 Standard Test Methods for Water Vapor Transmission of Materials, ASTM International, West Conshohocken, 2016.

5. Chinta, S.K., \& Gujar, P.D. Significance of moisture management for high performance textile fabrics. Int. J. Innov. Res. Sci. Eng. Technol. 2 (2013) 814-819.

6. G. Song, Improving comfort in clothing. Cambridge: Woodhead Publishing Limited, 2011.

7. Li, Y., Zhu, Q.Y., \& Yeung. K. W. Influence of thickness and porosity on coupled heat and liquid moisture transfer in porous textiles. Text. Res. J., 72 (2002) 435-446.

8. Majumdar, A., Mukhopadhyay, S. \& Yadav, R. Thermal properties of knitted fabrics made from cotton and regenerated bamboo cellulosic fibres. Int. J. Therm. Sci., 49 (2010) 2042-2048.

9. Yoon, H.N., \& Buckley, A. Improved comfort polyester. Part I: transport properties and thermal comfort of polyester/cotton blend fabrics. Text. Res. J., 54 (1984) 289-298. 